\title{
Measuring Child Poverty and Its Uncertainty: A Case Study of 33 European Countries
}

\author{
Ilaria Benedetti ${ }^{1}\left(\mathbb{D}\right.$, Gianni Betti $^{2, *(1)}$ and Federico Crescenzi ${ }^{3(1)}$ \\ 1 Department of Economics, Engineering, Society and Business, University of Tuscia, 01100 Viterbo, Italy; \\ i.benedetti@unitus.it \\ 2 Department of Economics and Statistics, University of Siena, 53100 Siena, Italy \\ 3 Department of Statistics, Computer Science, Applications "G. Parenti”, University of Florence, \\ 50134 Florence, Italy; federico.crescenzi@unifi.it \\ * Correspondence: gianni.betti@unisi.it; Tel.: +39-0577-233084
}

Received: 3 September 2020; Accepted: 30 September 2020; Published: 5 October 2020

check for updates

\begin{abstract}
Over the last few years, there has been increased interest in compiling poverty indicators for children, as well as in providing uncertainty measures that are associated with point estimates. In this paper, we provide point, variance, and interval confidence estimates of the at-risk-of-poverty rate indicator for 33 European countries. Using the 2018 EU-SILC survey, we analysed the spatial distribution of poverty by providing graphical representations at the national level. Our results reveal rates of child poverty that are higher than in the national estimates for most of the countries. By considering the computation of standard errors, we used the bootstrap method thanks to its convenient properties. It is worth noting that, for some countries, such as Finland, Belgium, and Ireland, the confidence intervals do not overlap. These results suggest differences among countries not only in terms of child poverty, but also in terms of social protection and the welfare state.
\end{abstract}

Keywords: child poverty; at-risk-of-poverty rate; uncertainty; bootstrap replication method

\section{Introduction and Motivation}

Over the past few decades, there has been increased interest in comparative analysis of poverty and social exclusion in European countries. In this context, measuring child poverty is a key topic in social science research, due to its importance for national governments and international organizations. Children and young people were some of the main victims of the crisis and ensuing austerity in advanced economies [1]. The Organization for Economic Cooperation and Development (OECD) reported increases in child poverty between 2008 and 2012, with 2.6 million more children living in poverty by the end of this period [2]. Goal 1 of the Sustainable Development Goals (SDGs), with its large number of corresponding targets and indicators, has increased the need to ensure successful outcomes for today's children by building the foundations our societies' future well-being [3].

Given the key role played by poverty indicators in designing and monitoring social progress in the EU, it is paramount to produce and communicate to the public measures of the inherent and unavoidable uncertainty of point estimates. Therefore, it is essential that the indicators that are used for measuring poverty are of sufficiently high quality, especially in terms of their accuracy, reliability, timeliness, and usability. Over the last few decades, there has been growing interest in statistical inference for inequality and poverty measures [4]. Measuring the uncertainty around data is a complex and challenging task, which may involve the use of sophisticated statistical methods as well as the adoption of econometric techniques and subjective judgement.

From a methodological point of view, the formulae for calculating standard errors also depend on the statistics to be computed. Therefore, in the case of complex statistics, such as the at-risk-of-poverty 
rate, where the poverty threshold is estimated on the basis of the survey data, the computation of standard errors is not straightforward [5]. Indeed, in this case there are two main sources of variability: one is related to the process of estimating the threshold, and the other arises from the estimate of the proportion of people living in poverty given the estimated threshold [6].

In this framework, a crucial role is played by estimates of poverty measures for children. The persistence of child poverty at rather high levels as compared to national poverty rates explains why reducing child poverty is now high on the social policy agenda of many OECD countries [1]. Despite the fact that several initiatives have been carried out of measuring and monitoring children's poverty over time and European countries, to the authors' knowledge the issues of uncertainty measurements have not yet been fully explored. Moreover, predictions and estimates are often fragile, resting on unsupported assumptions and limited data [7].

This paper focuses on a spatial distribution of child poverty while using the at-risk-of-poverty (AROP) indicator, which is part of the EU's headline indicator (AROPE) that is used to assess progress towards the Europe 2020 target of reducing the risk of poverty and social exclusion in the population to at least 20 million below the situation observed in 2010. We provided a graphical representation of the AROP at both the national level and for children using the 2018 EU-SILC data for 33 European countries. Therefore, a first contribution of this paper is to provide updated figures of the economic well-being at the national level of children living in European countries. This study also contributes to advancing the existing literature on the computation of standard errors and confidence intervals for children. To this aim, we provide an empirical application while using the bootstrap replication method, which gave us reliable information regarding the uncertainty of child poverty estimates information that is of crucial importance for policy makers [3]. We selected the bootstrap method because the bootstrap intervals are computationally inexpensive and easy to calculate, the same method applies to all the inequality measures used in the literature, and the bootstrap method automatically takes into account any bounds that apply to a particular measure. Given the potential advantages of bootstrapping, it appears worthwhile to consider its use as a tool for statistical inference for inequality measures. Indeed, Ref. [8] proved the validity of the bootstrap method for various indicators that are used in the context of inequality, mobility, and poverty measurement. Bootstrap techniques have been implemented for estimating the variance of several poverty indicators [9]. In the context of inequality measurement, the bootstrap was applied by [8-12], who recommended using it rather than asymptotic methods, especially in applications where the sample size is not large.

The rest of the paper is organized, as follows: in Section 2, after a brief review of the literature devoted to the definition of child poverty measures, we also illustrate the issue of measuring the uncertainty of the poverty indicators. Section 3 describes the EU Statistics on Income and Living Conditions (EU-SILC) survey, and discusses the main characteristics of the survey. The EU-SILC, which was launched by Eurostat in 2004, constitutes the main data source for constructing indicators of poverty and social exclusion, in the multi-country comparative context of the EU. Given that indicators based on the EU-SILC are sample estimates, they should be reported along with estimates of standard errors and confidence intervals, particularly if the indicators are used for policy decisions. Moreover, in Section 3 we focus on the bootstrap replication method used for estimating variance of the at-risk-of-poverty indicator. In Section 4, computational aspects and estimation results of standard errors at both the national level and for the two age-group categories of children (5-9 years old and 9-14 years old) are illustrated with a discussion of the main findings. Finally, in Section 5, we draw some conclusions and suggest some policy implications.

\section{Materials}

\subsection{Conceptualization of Children's Well-Being and Methods Used}

Children and young people were some of the main victims of the 2008 financial crisis. Most of the European Union (EU) saw an increase in child poverty between 2008 and 2012, with 2.6 million more 
children living in poverty by the end of this period [2]. In particular, Italy and Greece suffered from the economic crisis more than other European countries, such as the UK and France [13]. In 2011, 27\% of children that were aged less than 18 were at risk of poverty or social exclusion, and nearly a million more young people aged 15 to 24 were not in employment, education, or training across the EU [14].

The share of children at-risk-of poverty or social exclusion rate highest was in Romania and Bulgaria, while the lowest in the EU Nordic member states. In 2015, more than one-third of children were at risk of poverty or social exclusion in six European countries [15]: Romania (46.8\%), Bulgaria $(43.7 \%)$, followed by Greece (37.8\%), Hungary (36.1\%), Spain (34.4\%), and Italy (33.5\%). At the opposite end of the scale, the lowest shares of children at-risk-of poverty or social exclusion were recorded in Sweden (14.0\%), Finland (14.9\%) and Denmark (15.7\%), ahead of Slovenia (16.6\%), the Netherlands $(17.2 \%)$, the Czech Republic, and Germany (both 18.5\%). In approximately half the EU member states, the at-risk-of-poverty or social exclusion rate grew from 2010 to 2015, with the highest increases recorded in Greece (from $28.7 \%$ in 2010 to $37.8 \%$ in 2015), Cyprus (+7.1 percent points), and Italy ( +4.0 percent points).

The lack of progress in protecting children in the pre-crisis years highlights the existence of structural constraints, against which many of the rich welfare states have proved powerless. The persistence of child poverty at rather high levels when compared to national poverty rates and its rebound with the economic crisis explain why reducing child poverty is now high on the social policy agenda of many OECD countries [1].

To this aim, the new global SDGs, agreed to by governments in the world in 2015, set ambitious targets for social progress for the new generation of children and young people [16]. Goal 1 calls for reducing, by at least half, the proportion of men, women, and children of all ages living in poverty by 2030 [17]. Moreover, in Target 1.2, for the first time, a global poverty goal for children was included, thus recognizing the multidimensional nature of poverty. Achieving this Goal, of the SDGs ensure successful outcomes for today's children by building the foundations for our societies' future wellbeing [3]. Healthy and educated children are better able to fulfil their potential and contribute to society [18].

Several factors could affect child poverty and inequality [19]. In particular, demographic, economic, and policy measures play a role in influencing child poverty. In particular, the most significant factor in determining child poverty at the household level is the employment status of the parents [20]. Increased per-capita social spending, payment rates, social assistance, and higher rates of social assistance payments seem to be associated with decreased child poverty in countries over time [16]. In this context, only a range of policies addressing all of these factors can significantly and durably improve children's standards of living and reduce their exposure to poverty.

The study of children's well-being is characterized by a plurality of approaches and measures. In particular, the measurement of children's well-being has expanded in the past few years with the aim of pursuing policies at the social, national, or international level. In recent decades, a large part of the literature on social indicators has focused on developing functions that reduce multidimensional achievements to unidimensional values [21]. In this respect, Ref. [22] presents five methods used to choose and select domains by considering their practical relevance for children. Ref. [23] used the Capability Approach as a conceptual framework, based on the idea that children have and can define their capabilities. In this paper, the authors discuss gender disparities in children's well-being while using the Integrated Fuzzy and Relative (IFR) methodology.

Moreover, in the same stream of literature, [13] analyzed the impact of the economic crisis on children's well-being from a comparative European perspective while using a multidimensional and fuzzy methodology. Ref. [24] addresses issues concerning the derivation and measurement of the latent factor through the use of an item response modelling (IRM) framework to compare five European member states (Portugal, Italy, Ireland, Greece, and Spain) during the economic recession. Ref. [25] performed an economic poverty and inequality mapping of children in three age categories in Malta by applying a survey-based regression model of a logarithmic transformation of the total household 
equivalised income. Although a wide stream of literature addressed the multidimensional aspect of child poverty, relative monetary measures of poverty are crucial for evaluating children's well-being over time and they represent the main indicator to measure child poverty $([26,27])$.

\subsection{Estimating Uncertainty Measures for Poverty Indicators}

The issue of uncertainty measurement is crucial, since we are often interested in knowing whether poverty has increased or decreased over time, or in comparing poverty rate different geographical areas or socio-economic groups. In such cases, it is essential to have information regarding the sampling variability of the estimates. The formulae for calculating standard errors for poverty measures depend on the statistic to be computed. Many poverty indicators consist of headcounts with a fixed poverty threshold. Standard errors for all of the poverty measures of the well-known Foster-Greer-Thorbecke (FGT) class [28] may be estimated by using formulae that are similar to those used for proportion or mean. In the case of complex statistics, such as the at-risk-of-poverty rate where the poverty threshold is estimated on the basis of the survey data, computing standard errors can be quite difficult. One reason is that there are two main sources of variability: the estimated threshold and the estimated proportion given the estimated threshold [6]. Several authors have derived formulae for standard errors when the poverty line is estimated as a share of average or median income (for example [29]), while others have introduced alternative considerations, such as stochastic dominance over a range of poverty lines [30,31] and the need to treat household size as a random variable [32]. However, in the framework of non-linear statistics, the variance of non-linear estimators cannot be given in closed form in most cases. In addition, unbiased estimates of variances of non-linear estimators may not exist and exact variance formulae, therefore, cannot be estimated by conventional methods. In such cases, approximate variance estimation techniques must be used, including the linearization and resampling methods.

\section{Data and Methods}

\subsection{The EU Statistics on Income and Living Conditions (EU-SILC) Survey}

For our estimates, we used the 2018 EU-SILC survey and implemented a bootstrap replication method for estimating the variability of the at-risk-of-poverty indicator. The major source of comparative statistics on income and living conditions in Europe, the EU-SILC survey, aims to collect timely and comparable cross-sectional and longitudinal multidimensional microdata on income distribution, poverty, and social exclusion. It also covers various related EU living conditions and poverty policies, such as child poverty, access to health care and other services, housing, over-indebtedness, and quality of life. The EU-SILC survey contains both cross-sectional and longitudinal elements, with nationally representative samples of individuals 16 years and older. The EU-SILC survey is currently used to collect data in 33 countries. Information on social exclusion and housing conditions is mainly collected at the household level, while labour, education, and health information are obtained for persons aged 16 and over. The EU-SILC survey has been used to provide data on the structural indicators of social cohesion (e.g. at-risk-of-poverty rate, S80/S20). Since 2010, when the Europe 2020 strategy was first implemented, EU-SILC data have been used for monitoring poverty and social inclusion in the EU, and the Europe 2020 headline poverty target to reduce the number of people at risk of poverty and social exclusion by 20 million by 2020 was based on the EU-SILC instrument. In the EU-SILC surveys, income is the core variable. Data are mainly collected at the personal level and then aggregated at the household level to construct the total household income. Therefore, the reference income is household disposable income, which is usually converted into the equivalised household income while using a proper conversion scale. Equivalised disposable income is the total income of a household that is available for spending or saving, divided by the number of household members converted into equivalised adults. Household members are equivalised or made equivalent by the following so-called modified OECD equivalence scale, where 
the first household member aged 14 years or over counts as one person; each other household member aged 14 years or over counts as 0.5 ; and, each household member aged 13 years or less counts as 0.3 . This equivalised income is then attributed to the household and to each of its members and forms the required analytical variable for studying income-poverty and income-inequality indicators of the population. Of the Laeken indicators, which are key in the Europe 2020 strategy, we focused on the at-risk-of-poverty rate indicator (AROP). This indicator shows the share of persons who have an equivalised disposable income below the risk-of-poverty threshold (ARPT), which is set at $60 \%$ of the national median equivalised disposable income. This indicator is frequently disaggregated by age and gender, household type, tenure status, and work intensity. The AROP is a complex statistic, since it is based on a poverty threshold computed from the median of the income distribution. Therefore, ARPT needs to be estimated first. Let I be the set of units, such that their equivalised disposable income is below the ARPT. The AROP rate is then defined as:

$$
A \hat{R O P}=\frac{\sum_{i \in I<A \hat{R} P T} w_{i}}{\sum_{i} w_{i}}
$$

\subsection{Methodological Approach for Variance Estimation: The Bootstrap Replication Methods}

The replication methods based on repeated resampling of the parent sample may be applied in order to estimate variance for nonlinear statistics from complex samples. This class of methods includes the Bootstrap, Jackknife Repeated Replication (JRR), and Balanced Repeated Replication (BRR), and it is based on measures of observed variability among replications of the full sample.

The basic requirement is that the full sample is composed of a number of subsamples or replications, each of which has the same design and reflects the complexity of the full sample, and it is numbered using the same procedures. The various resampling procedures differ in the manner in which they generate replications from the parent sample and evoke the corresponding variance estimation formulae. Bootstrap inference for inequality measures has been used by various researchers $[8,10]$. The bootstrap is a method for recovering the distribution of a statistic by employing Monte Carlo simulation methods to approximate the small sample distribution (see $[33,34]$ for further details on the bootstrap). In the context of inequality measurement, the bootstrap was first applied in [10], where the authors considered the use of the bootstrap for computing interval estimates and testing hypotheses for decomposable measures of economic inequality.

Bootstrap intervals are computationally inexpensive and easy to calculate. Given the potential advantages of bootstrapping, it appears worthwhile to consider its use as a tool for statistical inference for inequality measures. In this paper, we make use of the so-called naïve bootstrap approach in order to estimate confidence intervals, as implemented in [35]. Other approaches to computing bootstrap confidence intervals are discussed in [36].

Let $X=\left(X_{1} ; \ldots ; X_{n}\right)^{\prime}$ denote a survey sample of $\mathrm{n}$ observations. The algorithm is implemented, as follows:

1. Draw $R$ independent samples $X_{1}^{*}, \ldots, X_{R}^{*}$ from $X$.

2. Compute the bootstrap replicate estimates $\hat{\lambda_{r}^{*}}=\hat{\lambda}\left(X_{r}^{*}\right)$ for each $X_{r}^{*} r=1, \ldots, R$ where $\hat{\lambda}$ denotes an estimator of the poverty indicator of interest.

3. Estimate the variance $V(\hat{\lambda})$ by using the variance of the $R$ bootstrap replicate estimates:

$$
\hat{V}(\hat{\lambda})=(R-1)^{-1} \sum_{r=1}^{R}\left(\hat{\lambda}\left(X^{r}\right)-R^{-1} \sum_{j=1}^{R} \hat{\lambda}\left(X^{j}\right)\right)^{2}
$$

4. The confidence interval at confidence level $(1-\alpha)$ is then calculated as:

$$
\left[2 \hat{\lambda}-\hat{\lambda}_{\left((R+1)\left(1-\frac{\alpha}{2}\right)\right)}^{*}, 2 \hat{\lambda}-\hat{\lambda}_{\left((R+1)\left(\frac{\alpha}{2}\right)\right)}^{*}\right]
$$


where $\hat{\lambda}_{(1)}^{*} \leq \hat{\lambda}_{(2)}^{*} \leq \ldots \leq \hat{\lambda}_{(R)}^{*}$. In the case of sampling designs that involve different strata, the observations are resampled independently within each stratum.

\section{Results and Discussion}

Table 1 reports AROP estimates for children at the national level of 33 European countries and they are geographically illustrated in Figure 1. As the figure shows, the AROP rate for children tends to be higher in Southern Europe and the United Kingdom, while Czech Republic, Malta, and Poland have the lowest child AROP rates.

Focusing on (relative) standard error estimates at the national level, it is essential to note that our standard error results show a satisfactory level of reliability, since the estimated coefficients of variation are lower than 5\%, as emphasized in [37]. Indeed, specifying the degree of precision is an important step when planning a sample survey, even if precision thresholds are generally survey specific and depend on the required reliability and resource-related political decision.

Table 1. Child poverty point estimates. Relative standard errors in parenthesis.

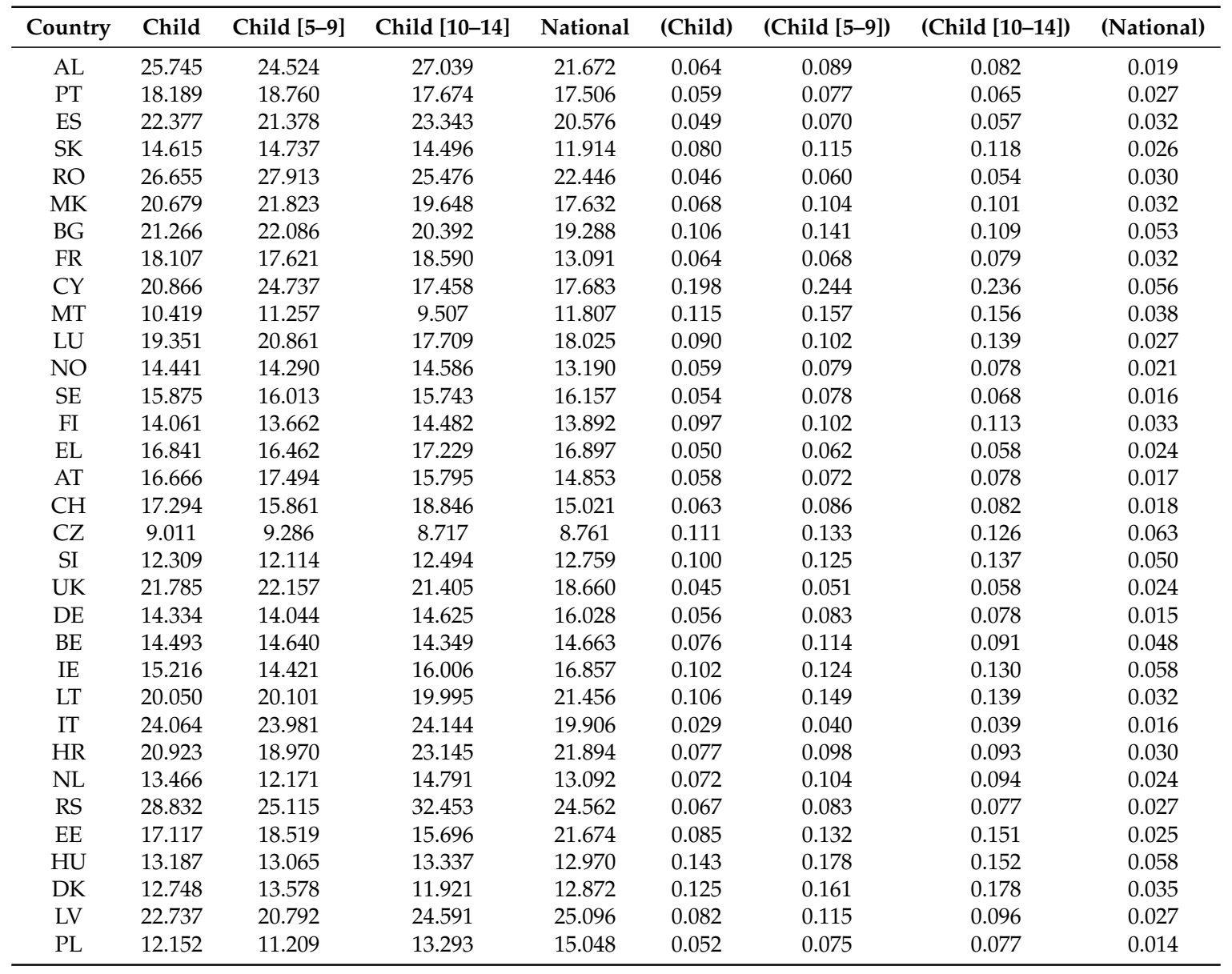




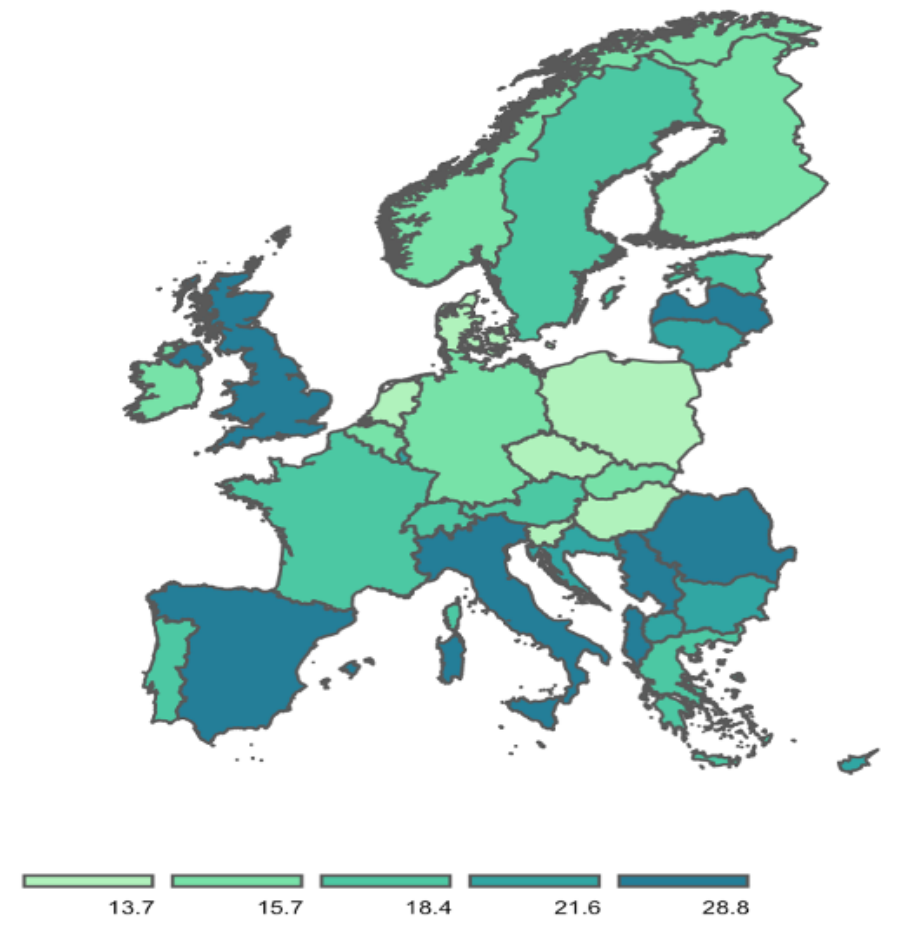

Figure 1. National at-risk-of-poverty (AROP) child poverty estimates.

It is evident from Figure 2 that, for most countries, the point estimates of the national AROP are higher than those observed for children. However, these do not differ significantly from each other, as shown by the estimates of confidence intervals. Remarkably, child poverty is significantly higher with respect to the national estimates in the UK, France, Albania, and Italy, while it is significantly lower in Poland and Greece. However, it is worth noting that while for some countries (such as Finland, Belgium, and Ireland) the confidence intervals clearly overlap, for others the overlap is minimal (e.g., Germany). Figure 2 also allows comparisons of child poverty across countries. For example, Italy is the fourth country in terms of the point estimate of the percentage of children who are at risk of poverty. This value is not significantly different from that observed in the UK, but it is certainly higher than the value observed in France. However, child poverty does not differ significantly between age classes, as suggested by confidence intervals in Figure 3.

The emergence of child poverty is an issue that can no longer be ignored. Only marginal measures have been introduced in the past few years and, in the majority of cases, those measures were fragmented and inadequate in most of the EU countries. Because the most significant factor in determining child poverty at the household level is the employment status of the parents, from a policy-making point of view, any plan to reduce poverty among children should address two issues: the low labour market participation of mothers, particularly in large households, and the redistributive inefficiency of child-related income transfers (allowances and tax deductions). Moreover, EU countries differ not only in terms of child poverty, but also in terms of family characteristics social protection systems and the economy and welfare state. The income protection system is clearly more robust and effective in some countries than in others. Greece, Italy, and Spain have less comprehensive, more fragmented social protection systems than their northern European counterpart. Moreover, the impact of unemployment plays a key role on poverty, in particular in the Mediterranean countries. In this respect, to be successful a policy should include, work-family reconciliation, in particular for women. A reform of child-linked income transfers, which should become more efficient. A successful policy should also include improvements in the minimum wage, child benefits and other social welfare, and tax credits. At the same time, structural policies should include the school system, with increased spending on education, health, and childcare and policies at local communities. Indeed, 
geographic/regional policies would be extremely useful in some countries, such as Italy, Spain, and Greece. A successful anti-poverty strategy for children also requires policies to cope with many of the consequences that income poverty has on children's material deprivation, physical and mental health, and educational achievements. These policies are particularly important for children in the poorest families whose parents are durably out of work and for whom social benefits are not large enough to lift them out of poverty.

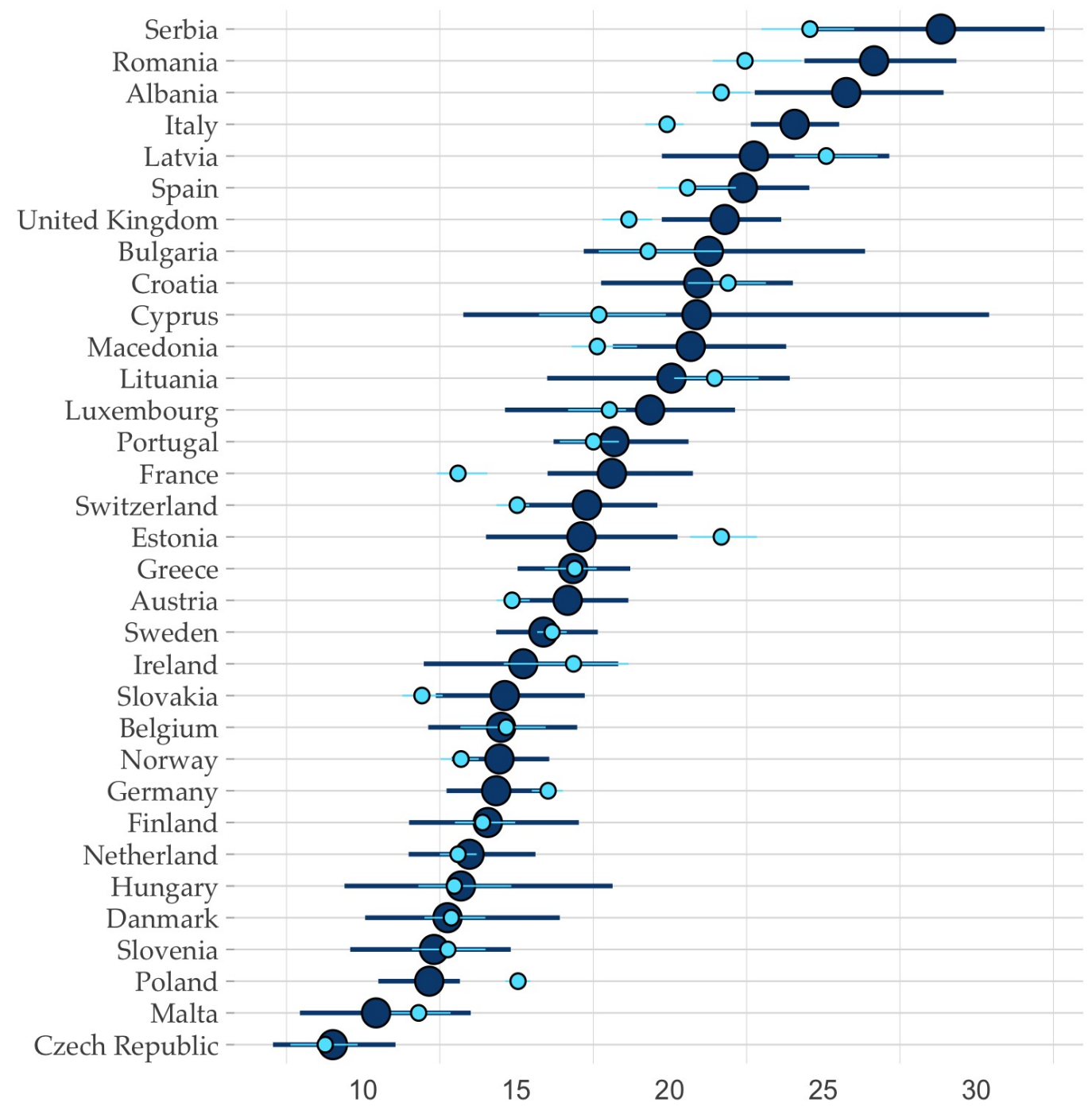

Figure 2. AROP child poverty estimates (darkblue) against national estimates (light blue). 


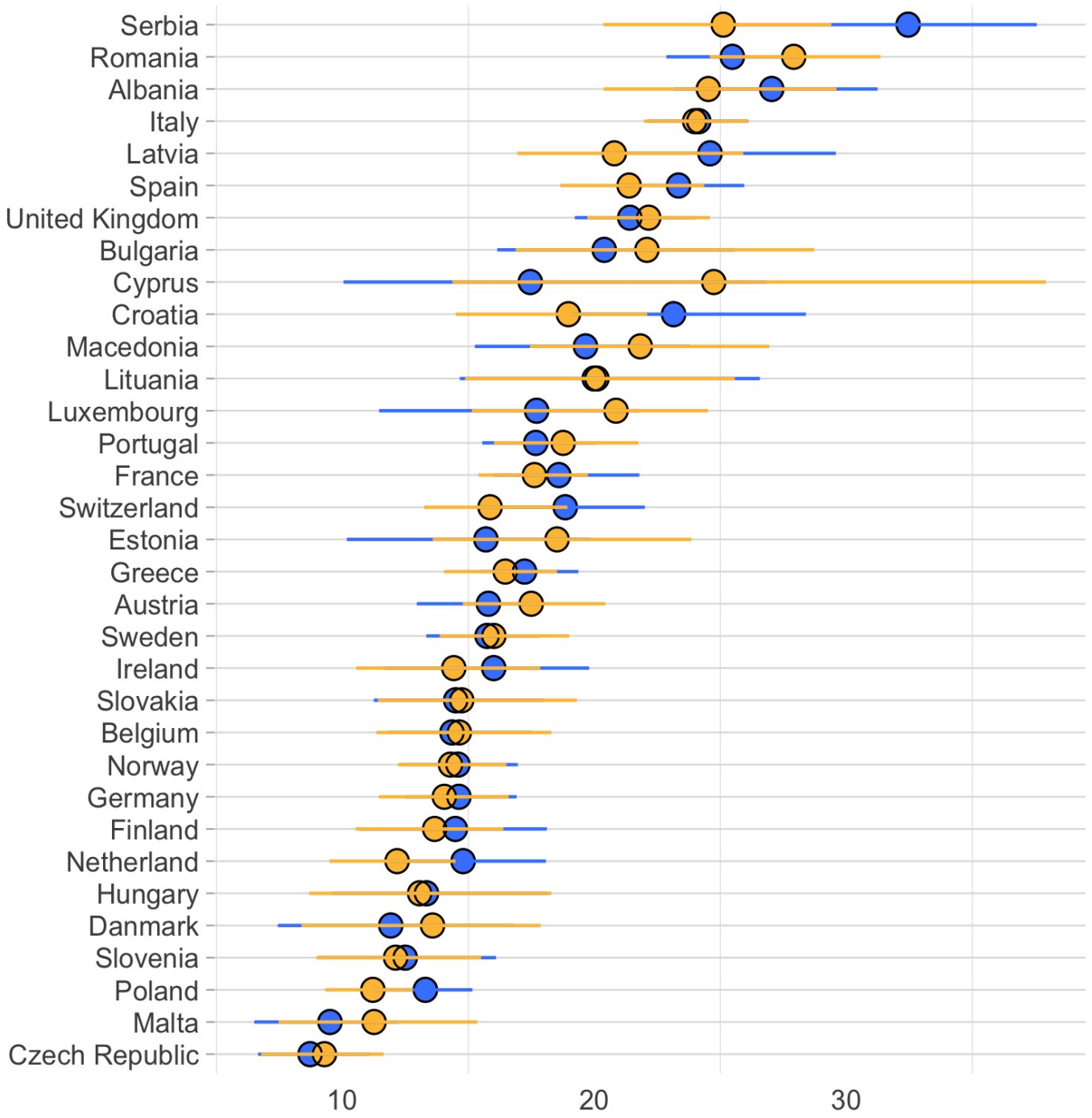

Figure 3. AROP child poverty estimates by age classes: [5-9] blue, [9-14] orange.

\section{Conclusions}

The statistics on children are extremely important for policy makers. They help them to monitor the effectiveness of policies that have been implemented and propose ad hoc policies to combat and eradicate poverty and exclusion halving education. The Sustainable Development Goals include the objective of halving child poverty by 2030. Achieving this goal requires investing in a comprehensive inclusive growth strategy. Policies promoting work-life balance, such as better quality and better paid jobs, are key to reducing child poverty.

In this paper, we use the 2018 EU-SILC survey to focus on the issue of measuring uncertainty in childrens' at-risk-of-poverty rate on 33 European countries. Information regarding the sampling variability of point estimates is essential when comparing poverty rates in different geographical areas or socio-economic groups. The computation of standard errors for the main official poverty measures is a complex task due to the characteristics of these indicators, which are often expressed as non-linear statistics. Moreover, communicating uncertainty aims to increase the transparency of the scientific assessment process and provide risk managers with a more informed evidence base by revealing the strengths and weaknesses of the evidence [38]. the bootstrap method is implemented in order to obtain relative standard errors for the at-risk-of-poverty rate for children. As can be seen from our estimation results, the AROP for children tends to be higher than the AROP computed at the national level: child poverty is significantly higher than the national estimates in the UK, France, Albania, 
and Italy, while it is significantly lower in Poland and Greece. Moreover, the AROP for children tends to be higher in Southern Europe, in particular in Serbia, Albania, Romania, and Italy, while Czech Republic, Malta, and Poland have the lowest AROP rates for children. Focusing on standard errors and confidence interval estimates, the confidence intervals for some countries (such as Finland, Belgium, and Ireland) clearly overlap, while, for others, the overlap is minimal (e.g. Germany). Although child poverty in Denmark and Hungary is not very high, the uncertainty level that is associated with these estimation results is considerable. These results suggest differences among European countries not only in terms of child poverty, but also in terms of family characteristics, social protection systems, and the economy and welfare state.

Author Contributions: G.B. is the corresponding author. He coordinated the work, conceived and shaped the research idea, provided support in building the case study and interpreting the results by writing-reviewing and editing. I.B. conducted the literature review and drafted the following paragraphs: Introduction, Materials, Data, Methods, and Conclusion. F.C. has conducted the data analysis and drafted the following paragraphs: Methodological approach for variance estimation: the bootstrap replication methods and Results and discussion. All authors discussed the results and commented on the manuscript, contributing to its revision and finalization. All authors have read and agreed to the published version of the manuscript.

Funding: This research received no external funding.

Conflicts of Interest: The authors declare no conflict of interest.

\section{Abbreviations}

The following abbreviations are used in this manuscript:

$\begin{array}{ll}\text { AROP } & \text { at-risk-of-poverty rate } \\ \text { ARPT } & \text { at-risk-of-poverty threshold } \\ \text { BRR } & \text { Balanced Repeated Replication } \\ \text { EU-SILC } & \text { EU Statistics on Income and Living Conditions } \\ \text { EU } & \text { European Countries } \\ \text { FGT } & \text { Foster-Greer-Thorbecke } \\ \text { IFR } & \text { Integrated Fuzzy and Relative } \\ \text { JRR } & \text { Jackknife Repeated Replication } \\ \text { OECD } & \text { Organization for Economic Cooperation and Development } \\ \text { SGDs } & \text { Sustainable Development Goals }\end{array}$

\section{References}

1. Cantillon, B.; Chzhen, Y.; Handa, S.; Nolan, B. Children of Austerity: Impact of the Great Recession on Child Poverty in Rich Countries; Oxford University Press: Oxford, UK, 2017.

2. Fanjul, G. Children of the Recession: The Impact of the Economic Crisis on Child Well-Being in Rich Countries. Innocenti Report Card 12; ERIC: Florence, Italy, 2014.

3. Brazier, C. Building the Future: Children and the Sustainable Development Goals in Rich Countries; Innocenti Report Card 14; UNICEF: Geneva, Switzerland, 2017.

4. Manski, C.F. Communicating uncertainty in official economic statistics: An appraisal fifty years after Morgenstern. J. Econ. Lit. 2015, 53, 631-53. [CrossRef]

5. Betti, G.; Gagliardi, F.; Lemmi, A.; Verma, V. Subnational indicators of poverty and deprivation in Europe: Methodology and applications. Camb. J. Reg. Econ. Soc. 2012, 5, 129-147. [CrossRef]

6. Verma, V.; Betti, G. Taylor linearization sampling errors and design effects for poverty measures and other complex statistics. J. Appl. Stat. 2011, 38, 1549-1576. [CrossRef]

7. Manski, C.F. Communicating uncertainty in policy analysis. Proc. Natl. Acad. Sci. USA 2019, 116, 7634-7641. [CrossRef] [PubMed]

8. Biewen, M. Bootstrap inference for inequality, mobility and poverty measurement. J. Econom. 2002, 108, 317-342. [CrossRef]

9. Palmitesta, P.; Provasi, C.; Spera, C. Confidence interval estimation for inequality indices of the Gini family. Comput. Econ. 2000, 16, 137-147. [CrossRef] 
10. Mills, J.A.; Zandvakili, S. Statistical inference via bootstrapping for measures of inequality. J. Appl. Econom. 1997, 12, 133-150. [CrossRef]

11. Palmitesta, G.; Provasi, C. Asymptotic and bootstrap inference for the generalized Gini indices. Metron 2006, 64, 107-124.

12. Biewen, M. Income Inequality in Germany during the 1980s and 1990s. Rev. Income Wealth 2000, 46, 1-19. [CrossRef]

13. D'Agostino, A.; Gagliardi, F.; Giusti, C.; Potsi, A. Investigating the impact of the economic crisis on children's wellbeing in four European countries. Soc. Sci. Res. 2019, 84, 102322. [CrossRef]

14. Eichhorst, W.; Hinte, H.; Rinne, U. Youth Unemployment in Europe: What to Do about It? Technical Report; IZA Policy Paper, 2013. Available online: https://www.iza.org/publications/pp/65/youth-unemploymentin-europe-what-to-do-about-it (accessed on 1 September 2020)

15. EUROSTAT, Universal Children's Day. Available online: https://epthinktank.eu/2016/11/20/universalchildrens-day-2016/ (accessed on 5 October 2020).

16. UNICEF A World Free from Child Poverty: A Guide to the Tasks to Achieve the Vision; UNICEF: Geneva, Switzerland, 2017.

17. Nations, U. World population prospects: The 2015 revision. U. N. Econ. Soc. Aff. 2015, 33, 1-66.

18. Ndubuka, N.N.; Rey-Marmonier, E. Capability approach for realising the Sustainable Development Goals through Responsible Management Education: The case of UK business school academics. Int. J. Manag. Educ. 2019, 17, 100319. [CrossRef]

19. D'Agostino, A.; Grilli, G.; Regoli, A. The determinants of subjective well-being of young adults in Europe. Appl. Res. Qual. Life 2019, 14, 85-112. [CrossRef]

20. Gornick, J.C.; J'antti, M. Child Poverty in Comparative Perspective: Assessing the Role of Family Structure and Parental Education and Employment; LIS Working Paper Series, Technical Report, 2011. Available online: https:/ /ideas.repec.org/p/lis/liswps/570.html (accessed on 28 August 2020).

21. Mauro, V.; Biggeri, M.; Maggino, F. Measuring and monitoring poverty and well-being: A new approach for the synthesis of multidimensionality. Soc. Indic. Res. 2018, 135, 75-89. [CrossRef]

22. Biggeri, M.; Mehrotra, S. Child poverty as capability deprivation: How to choose domains of child well-being and poverty. In Children and the Capability Approach; Palgrave Macmillan: London, UK, 2011; pp. 46-75.

23. D'Agostino, A.; Giusti, C.; Potsi, A. Gender and Children's wellbeing: Four Mediterranean countries in perspective. Child Indic. Res. 2018, 11, 1649-1676. [CrossRef]

24. Grilli, G.; D'Agostino, A.; Potsi, A. Social Participation and Safety Deprivation of Children in Italy: PIIGS Countries in Perspective. Child Indic. Res. 2018, 11, 159-184. [CrossRef]

25. Betti, G.; Caruana, E.; Gusman, S.; Neri, L. Economic poverty and inequality at regional level in Malta: Focus on the situation of children. Econ. Reg. 2015, 114-122. [CrossRef]

26. Corak, M.; Fertig, M.; Tamm, M. A portrait of child poverty in Germany. Rev. Income Wealth 2008, 54, 547-571. [CrossRef]

27. Richardson, D.; Hoelscher, P.; Bradshaw, J. Child well-being in Central and Eastern European countries (CEE) and the Commonwealth of Independent States (CIS). Child Indic. Res. 2008, 1, 211-250. [CrossRef]

28. Foster, J.; Greer, J.; Thorbecke, E. A class of decomposable poverty measures. Econometrica 1984, 52, 761-766. [CrossRef]

29. Preston, I. Sampling distributions of relative poverty statistics. J. R. Stat. Soc. Ser. C (Appl. Stat.) 1995, 44, 91-99. [CrossRef]

30. Davidson, R.; Duclos, J.Y. Statistical inference for stochastic dominance and for the measurement of poverty and inequality. Econometrica 2000, 68, 1435-1464. [CrossRef]

31. Mehdi, T. Stochastic Dominance Approach to Measuring Child Development. Child Indic. Res. 2019, 12, 1567-1588. [CrossRef]

32. Thuysbaert, B. Inference for the measurement of poverty in the presence of a stochastic weighting variable. J. Econ. Inequal. 2008, 6, 33-55. [CrossRef]

33. Efron, B.; Stein, C. The jackknife estimate of variance. Ann. Stat. 1981, 9, 586-596. [CrossRef]

34. Efron, B.; Tibshirani, R.J. An Introduction to the Bootstrap; CRC Press: Boca Raton, FL, USA, 1994.

35. Alfons, A.; Templ, M. Estimation of Social Exclusion Indicators from Complex Surveys: The R Package Laeken. In KU Leuven, Faculty of Business and Economics Working Paper; Faculty of Business and Economics: Beijing, China, 2012. 
36. Davison, A.C.; Hinkley, D.V. Bootstrap Methods and Their Application; Number 1; Cambridge University Press: Cambridge, UK, 1997.

37. Ardilly, P. Les Techniques de Sondage; Editions Technip: London, UK, 2006.

38. Committee, E.S.; Hardy, A.; Benford, D.; Halldorsson, T.; Jeger, M.J.; Knutsen, H.K.; More, S.; Naegeli, H.; Noteborn, H.; Ockleford, C.; et al. Guidance on the use of the weight of evidence approach in scientific assessments. EFSA J. 2017, 15, e04971.

(C) 2020 by the authors. Licensee MDPI, Basel, Switzerland. This article is an open access article distributed under the terms and conditions of the Creative Commons Attribution (CC BY) license (http://creativecommons.org/licenses/by/4.0/). 